\title{
Prácticas periodísticas en Aguascalientes: estructuras de interpretación para acercarse al acontecer
}

\author{
Salvador de LeÓN VÁzQuez* \\ sdeleon@correo.uaa.mx
}

\begin{abstract}
Este artículo presenta una síntesis de los resultados obtenidos a partir de la investigación "La producción de noticias en Aguascalientes. Cómo se construye el acontecer periodístico". El estudio busca llegar a una comprensión de cómo son elaboradas las noticias en una ciudad de la provincia mexicana mediante un estudio de caso referido a una empresa noticiosa de prensa escrita. Para el acercamiento a este fenómeno se partió de los postulados de la sociología de la producción de noticias y se integró un diseño metodológico basado en las técnicas de la observación participante y de la entrevista. El resultado es la caracterización de las prácticas que los periodistas aguascalentenses de prensa diaria llevan a cabo para elaborar reportes informativos de la realidad a través de los cuales contribuyen a la construcción del acontecer periodístico local. Dichas prácticas son rutinas de producción que sintetizan estructuras de socialización y de interpretación respecto al entorno.
\end{abstract}

This article presents a synthesis of the results from the study "The production of news in Aguascalientes: How the journalistic happening is built". Through a case study of a local newsmedia, this research looking for to arrive to an understanding about how the news are produced in a mexican city. Thinking in the approach to the phenomenon, it was used the thoretical perspective called Sociology of News Production, and it was integrated a methodolgical design based on the participating observation and interview techniques. The result is a description of the practices that the journalists from Aguascalientes' press do in order to make reports from reality. This practices are production routines and synthesize structures of socialization and interpretation about the environment.

*Universidad Autónoma de Aguascalientes. 


\section{Puntos DE PARTIDA}

La producción de noticias como actividad cotidiana de los hombres de la prensa en el contexto de la organización periodística a la cual pertenecen, es la clave de la articulación de este estudio. La pertinencia para abordar la forma en la que los periodistas elaboran noticias radica en la necesidad de conocer cómo ciertos procesos sociales son vistos, narrados y tratados por las instituciones de medios que en nuestra sociedad se encuentran legitimadas para hacerlo. Las noticias, entonces, son verdaderas construcciones del acontecer que es significativo desde ciertas lógicas y estructuras de interpretación del entorno. Entender cómo operan esas lógicas de significación de la realidad es el objetivo que dio origen a la investigación de la cual aquí se presentan de manera sintética los resultados.

Aguascalientes es una ciudad pequeña, capital de un estado pequeño de la provincia mexicana, ubicado en la región CentroNorte del país. En este sitio se ha llevado a cabo un proceso vertiginoso de cambio, de un estado agrícola a uno industrial, en relativamente poco tiempo (alrededor de 20 años). Frente a una gran dinámica económica, cambios socioculturales (al parecer como efectos de la primera) y cambios en la configuración política (con la entrada de la oposición, representada por el Partido Acción Nacional, al gobierno municipal y estatal en 1995 y 1998, respectivamente), surgen diferentes preguntas que permiten delinear la construcción de un objeto de estudio: bajo estas condiciones, ¿qué pasa con los procesos de significación del entorno, específicamente con el periodismo? ¿En qué situación y por medio de qué prácticas los periodistas aguascalentenses generan sentido de su realidad y la convierten en noticias?; en pocas palabras, frente a este estado de las cosas, ¿qué pasa con el periodismo local?, ¿cómo se producen las noticias en Aguascalientes?

Con la intención de llegar a este conocimiento, fue planteado este acercamiento empírico a las prácticas periodísticas realizadas en esta ciudad. El estudio fue delimitado desde tres puntos de vista: 
1. El proceso comunicacional: la producción de noticias se ubica en el polo emisor de la comunicación, lo que permite la adopción de un cuerpo teórico relacionado con el estudio de los emisores, en este caso la sociología de la producción de noticias.

2. La situación geográfico-política: la ciudad de Aguascalientes, la cual los propios periodistas utilizan como circunscripción para elaborar noticias.

3. El medio noticioso: prensa escrita, caracterizado para esta investigación por un diario local (estudio de caso).

\section{Preguntas en ESPERA DE RESPUESTA}

¿Cómo se producen las noticias en la prensa escrita de Aguascalientes?, es la pregunta principal que sirvió como eje para la elaboración de esta investigación. El planteamiento de esta pregunta resultó más estratégico de lo que se esperaba, pues más que encontrar respuestas, permitió encontrar nuevos cuestionamientos sugerentes, vetas de conocimiento acerca del periodismo y sus procesos, que pueden ser abordados. Debo decir que el fenómeno de la producción noticiosa es bastante complejo y, adelantándome a las conclusiones resultantes, es necesario señalar que un fruto importante de este estudio fue el planteamiento de nuevas preguntas y dudas que bien podrían convertirse en una agenda de investigación para abordar el estudio de las prácticas periodísticas locales. ${ }^{1}$

El objetivo bajo el cual se planteó el estudio puede expresarse como la posibilidad de conocer y comprender cómo se producen las noticias en la prensa escrita de Aguascalientes mediante el análisis de las prácticas realizadas por los periodistas para producir noticias en uno de los principales periódicos que fun-

${ }^{1}$ Estas preguntas de fondo pueden enumerarse de la siguiente manera: 1) en el contexto actual, bajo las condiciones sociales que hoy vivimos, ¿qué es el periodismo?; 2) ¿qué significan las noticias como narraciones sociales del mundo y su acontecer?; 3) ¿cómo contribuye la construcción de noticias al pensamiento colectivo?, y 4) ¿cuál es el punto de unión entre lo individual (la práctica) y lo social (la representación que hace posible la generación de noticias? 
cionan en esta ciudad. Esto implica centrarse en el contexto organizacional de una las empresas periodísticas más importantes de la localidad, que impone rutinas de producción noticiosa a sus trabajadores, las cuales a su vez sintetizan estructuras de socialización, interpretación y significación de ciertos aspectos de la realidad que son recogidos y transformados en noticias.

\section{ESTUDIO SOCIOLÓGICO DE LA PRODUCCIÓN DE NOTICIAS}

La perspectiva teórica que sirve para enmarcar esta investigación es la sociología del periodismo o sociología de la producción de noticias. Puesto que otros autores han explicado profundamente este conjunto de postulados (v.g. Cervantes 1993, 1994, 19951996, 1995a, 1996, 2000; González Molina 1986, 1987, 1988; Hernández 1992, 1995, 1997, 2000), tan sólo delinearé algunas premisas generales que presentan los ejes conceptuales en los que esta perspectiva se sustenta, con la finalidad de orientar la presentación de los resultados del estudio.

\section{La noticia es el resultado de un proceso social complejo.}

Las noticias no son el resultado de decisiones individuales, sino de procesos sociales complejos en donde las organizaciones de medios tienen un lugar especial (Hernández 1992: 236). Esto implica que la noticia es una construcción social elaborada por medio de prácticas sociales complejas que tienen que ver con procesos de socialización, institucionalización y valoración de las formas legitimadas de narrar la realidad.

2. La organización periodística es una organización burocrática.

Señalar que las empresas noticiosas son burocráticas es hacer hincapié en su sistema operativo basado en una línea vertical de autoridad por medio de la cual se presenta una división social del trabajo informativo. Esta estructura burocrática permite también 
la formación de canales formales a través de los cuales fluye la información, se especializan las actividades laborales y se centralizan las tomas de decisión en los niveles altos (McNair 1998: 62; Tuchman 1983: 34; Fishman 1983: 162; Gans 1980: 84; Sigal 1973: 14).

3. La producción de noticias se efectúa mediante rutinas.

Las rutinas periodísticas son pautas de actividades sancionadas y consensadas por la organización y por las comunidades de periodistas como las formas "correctas" para elaborar noticias. A su vez, la rutinización tiene su origen en la incertidumbre de no saber qué es exactamente noticia entre una gama de acontecimientos que el reportero presencia día con día. Las rutinas contribuyen a reducir esa incertidumbre porque otorgan pautas normativas acerca de la elaboración de las noticias. Los estudiosos han clasificado las rutinas periodísticas en dos categorías: a) las de acopio de la información (cobertura noticiosa), y b) las de tratamiento de la información (selección, jerarquización y presentación de las noticias) (Wolf 1987: 248; Tuchman 1983: 35; Gans 1980: 78; Hernández 1995: 22).

4. Los valores noticiosos considerados como una paraideología periodística que permite reconocer acontecimientos susceptibles de ser transformados en noticias.

Los valores noticiosos son categorías construidas para el análisis de las noticias a partir de la identificación de ciertos aspectos que los periodistas reconocen como noticiables en los acontecimientos con los que tienen contacto. Mediante los criterios que los periodistas han interiorizado a partir de un proceso complejo de socialización y que además consensan en el ejercicio cotidiano de su profesión, es posible que otorguen más interés a algunos acontecimientos respecto a otros porque resultan más noticiables. Estos criterios de valoración son elementos que los periodistas utilizan en la 
construcción de las noticias. Ejemplos de valores noticiosos son la objetividad, la proximidad de un acontecimiento respecto al contexto de referencia, la actualidad de la información, la exclusividad, la notoriedad otorgada a una fuente informativa, entre otros (Cervantes 1995-96: 92; Gans 1980: 203; Sigal 1973: 88).

5. El grado de autonomía de los sujetos individuales frente a las determinaciones impuestas por las organizaciones periodísticas.

Puesto que las organizaciones de medios imponen rutinas y criterios de valoración noticiosa de los acontecimientos, resulta importante reconocer hasta qué punto los sujetos individuales tienen la posibilidad de tomar decisiones en el proceso de la elaboración de noticias. Esta situación se relaciona con el lugar que cada actor ocupa en dicho proceso: reporteros, editores, directivos, fuentes informativas, etcétera (Gans 1980; Williams 2000).

6. Niveles de análisis en el estudio de la producción de mensajes.

En el análisis de la producción de mensajes se reconocen tres espacios principales de interacción: ocupacional, organizacional e institucional (Hirsch 1980: 265; Dimmick y Coit 1983: 361; McQuail 1994: 188; Grossberg et al. 1998: 59). Este estudio se ha enfocado en el nivel organizacional (sin pretender que se encuentra aislado de los otros dos) debido a que se trata del primer contexto en el que se realiza la producción de noticias.

\section{ACERCAMIENTO EMPÍRICO A LAS PRÁCTICAS PERIODÍSTICAS EN Aguascalientes}

El estudio sociológico de la producción de noticias es de tipo comprensivo, no busca la explicación de los fenómenos sino su comprensión. Derivado del pensamiento interaccionista en donde esta perspectiva encuentra fundamentos teórico-metodológicos, se ha integrado un análisis cualitativo basado en dos técnicas de investigación aplicadas en un estudio de caso: 
1. Observación participante. Fue diseñada en tres fases de acercamiento al escenario. Durante la primera se buscó la introducción al escenario y el diálogo de la teoría con la realidad. En la segunda se reconocieron los elementos organizacionales de la empresa periodística, mientras que en la tercera se acompañó a los reporteros en su labor cotidiana de realizar noticias. A su vez, la observación participante estuvo centrada en tres aspectos principales de acuerdo con el protocolo o guía de observación: a) actores, b) acciones que se realizan, y c) contextos. En sus tres fases la observación se extendió desde junio de 1999 a septiembre de 2000.

2. Entrevistas. Se llevaron a cabo entrevistas a profundidad con diversos tipos de actores (reporteros, jefes y directivos). La guía de entrevista fue integrada con base en los siguientes aspectos: la idea que el sujeto tiene acerca de qué es noticia, las acciones que se utilizan para realizarlas, la valoración que hacen de los acontecimientos para considerarlos noticias, y la percepción que tienen de sí mismos como periodistas.

\section{EL ESCENARIO}

Para elegir el escenario se consideró la oferta periodística más consolidada compuesta por los tres diarios locales principales. El diario elegido al que se logró fácil acceso fue fundado en 1954, y desde entonces se ha publicado sin interrupciones. ${ }^{2}$ Este periódico forma parte de una pequeña cadena familiar de tres diarios que se ubican en tres de las ciudades más importantes de la zona del bajío: León, Irapuato y Aguascalientes.

Acerca de sus características particulares, se puede señalar que el diario se encuentra constituido por cuatro secciones edito-

\footnotetext{
${ }^{2}$ Por petición expresa me es imposible citar el nombre de la organización periodística en la que esta investigación se funda, lo mismo que el nombre de los actores que fueron observados y entrevistados. Sin embargo, esta situación no es obstáculo para el desarrollo de este estudio, puesto que no importan los nombres sino los actores (como construcción analítica) y las acciones que llevan a cabo en el proceso de la elaboración de noticias en el contexto de la ciudad de Aguascalientes.
} 
riales, cada una con su jefe responsable y con su cuerpo de reporteros (a excepción de la sección "Nacional e Internacional"). Un aspecto muy importante y que llama la atención, es la carencia de un jefe de información que se encargue de la organización de la cobertura diaria; de ahí que en este diario local no existan las reuniones de pauta.

Durante el tiempo de observación, en la sección "Local” (también llamada "primera plana") había nueve reporteros, dos de los cuales eran policiacos. Cada uno de ellos se ocupaba de diversas fuentes con diferentes naturalezas temáticas y poco relacionadas entre sí. Por ejemplo, el reportero que cubría sindicatos, al mismo tiempo atendía el municipio de Jesús María (casi conurbado con la capital), los colegios de profesionistas (excepto contadores y notarios, que pertenecían a otra reportera), asociaciones civiles y el Partido Acción Nacional, entre otras. Como puede observarse, la asignación de fuentes informativas es dispersa. Asimismo, cada reportero tiene la obligación de entregar cinco noticias diariamente a excepción de los reporteros policiacos, cuya obligación es otorgar material necesario para llenar una plana cada uno, dos planas en total.

Por otro lado, la sección "Nacional e Internacional" no tiene reporteros y mucho menos corresponsales. Los insumos de la sección para publicar noticias son los materiales enviados por las agencias de información a las que el periódico se encuentra suscrito. En el caso de la sección "Sociales y Espectáculos", las reporteras fueron siempre mujeres y su número fluctuó entre dos y cuatro durante el periodo de observación. Una de las características notables en esta sección es una gran rotación de personal. Cuando las fases de observación concluyeron (septiembre de 2000), la planta laboral de esta sección se había renovado por completo con relación al inicio (junio de 1999). La sección de "Deportes", por su parte, presentaba una configuración completamente contraria; además del editor, la sección contaba con tres reporteros varones que se mantuvieron durante todo el tiempo. La exigencia de noticias para los reporteros de estas dos secciones era de ocho diariamente. Una situación que vale la pena comentar 
es que uno de los reporteros de deportes lo era también de policía $y$, por lo tanto, cada día entregaba sus ocho noticias deportivas más la plana policiaca que le correspondía.

\section{RESULTADOS}

\section{A) Rutinas de producción noticiosa}

1. Día típico en la organización noticiosa

El día típico es ideal. Se trata de una construcción teórica de las actividades que se desarrollan en la organización durante un día de trabajo. El investigador describe un día típico para abordar la labor cotidiana de los periodistas. Su descripción es fruto de varias semanas de observación en el escenario. No se trata de un día real, debido a que cada día tiene características diferentes de acuerdo con cada una de las secciones. Es también diferente si se consideran el fin de semana o los días "hábiles" (para los reporteros todos los días son hábiles). Una vez hecha esta aclaración, ${ }^{3}$ señalaré que el día típico en la organización fue construido con base en los dos escenarios en los cuales se producen las noticias: en la sala de redacción y en el exterior (ámbitos noticiales).

En la sala de redacción el día típico se articula a partir de una serie de actividades programadas (tiempos y movimientos) que todos los trabajadores del diario deben respetar con la finalidad de tener un flujo continuo de acciones que concluyen con la venta del diario a las cinco de la mañana. Esto implica la programación de las actividades realizadas por reporteros, jefes, directivos y trabajadores. Consiste en el vaciado de la información, su tratamiento y el proceso de producción física del diario (impresión).

El día inicia en la sala de redacción con las reporteras de "Sociales", que deben escribir sus notas entre las diez de la maña-

${ }^{3}$ Cervantes, en una reflexión crítica acerca de las maneras de abordar el análisis sociológico de la producción de noticias en América Latina, critica la utilización de metáforas como la del "día típico en la organización”, porque considera que es superficial (2000: 179). Frente a esto vale señalar que la investigación no se limita a la descripción de un día típico, sino que tal metáfora es utilizada como una estrategia para iniciar el análisis de las rutinas de producción periodística. 
na y las dos de la tarde. Al mismo tiempo que redactan, reciben llamadas de personas que desean publicar sus eventos sociales. Estas reporteras no realizan coberturas debido a que la información telefónica es su materia prima noticial, aunque esporádicamente son enviadas a cubrir algunos eventos sociales y culturales. El material debe encontrarse listo a las dos de la tarde, porque ésa es la hora de entrada de la editora, quien procede al proceso de tratamiento de la información (selección, jerarquización y presentación de las noticias). Los reporteros de "Local" y "Deportes" llegan en el transcurso de la tarde, a partir de las dos, a entregar su material.

La sección de "Sociales" marca la pauta de trabajo para los departamentos que funcionan en la empresa. Esto es posible porque "Sociales" es la que inicia sus procesos (desde la redacción hasta la impresión) a una hora más temprana. A las cinco de la tarde llega el primer corrector, por lo que las noticias de "Sociales" ya deben haber sido trabajadas para que el corrector pueda empezar con su labor de revisión ortográfica y gramatical. De las siete a las nueve los demás correctores van llegando en forma escalonada para continuar el proceso conforme se van teniendo listas las demás secciones. A las siete llegan también los formadores, por lo que los esquemas de las planas de la sección de "Sociales" deben haberse concluido para que procedan a la formación electrónica de las planas. A las diez de la noche inician turno los trabajadores de fotomecánica; para tal hora las planas formadas deben haber sido pasadas a la procesadora de negativos para que fotomecánica pueda comenzar a revelar. Las placas de las páginas de "Sociales" deben estar listas a la medianoche, cuando los trabajadores de prensa están listos para iniciar el primer tiro. Conforme cada departamento (corrección, formación, fotomecánica y prensa) va terminando con la sección de "Sociales", deben continuar con las demás, en el siguiente orden: "Deportes", "Nacional e Internacional" y "Local" en donde se incluye, por supuesto, la sección policiaca, cuyo reportero entrega su material entre las doce de la noche y la una de la mañana (uno de los motivos por lo cual la sección "Local" se deja al final). 
Acerca del día típico en el exterior, se puede decir que es el dominio de los reporteros y se caracteriza por las visitas a los ámbitos noticiales. Puesto que las características de las fuentes informativas que los reporteros visitan son muy diferentes, es difícil articular una pauta de actividades. Así, la actividad fundamental es visitar y concertar citas con las fuentes que la organización les ha asignado.

\section{RUTINAS DE RECOPILACIÓN DE LA INFORMACIÓN}

La observación se centró específicamente en la sección "Local”, en donde se publican las noticias "importantes" (políticas, económicas, policiacas y las referidas a otros procesos socioculturales como la educación o la religión, por ejemplo). Las condiciones organizacionales con la carencia de un jefe de información, obliga a los reporteros a ciertas prácticas para sustituir las pautas y órdenes de trabajo. De esta manera, los reporteros llevan a cabo diariamente la rutina de visitar ciertas fuentes informativas que el periódico les ha asignado. Las fuentes asignadas a los reporteros funcionan como una red de fuentes que fragmentan la realidad como una forma de acercarse a ella. Las fuentes permiten versatilidad de acuerdo con su naturaleza y cómo el reportero interpreta su cobertura.

\section{Ronda por las fuentes}

Ante la falta de una pauta de cobertura para atender durante el día (debido a la inexistencia de un jefe de información), el método más común para obtener información por parte de los reporteros es la entrevista directa. Los reporteros buscan personalmente a los representantes de las fuentes informativas y concertan citas con ellos. No hay una lógica evidente para estructurar la cobertura, más que la de atender la cuota noticial de cinco reportes diarios como mínimo que la organización exige en el marco de una asignación de fuentes específicas. Cada reportero está obligado a dar cobertura a las fuentes que tiene asignadas y a no invadir otras 
que no se le han otorgado (mediante lo cual la organización mantiene el control sobre la cobertura).

Existen pocas fuentes organizadas y burocratizadas para lograr profesionalmente el acceso a los medios noticiosos y que ofrecen soportes informativos de forma sistemática, como ruedas de prensa, boletines, información variada. Esto último es el caso de las fuentes informativas más grandes e importantes, como el Gobierno del estado, la Presidencia Municipal o el Congreso local. Los reporteros que cubren estas fuentes suelen ser los que han escalado estatus en la organización (principalmente por su antigüedad y, junto con ello, por el grado de socialización e interiorización de los criterios organizacionales que les permiten satisfacer las expectativas de la empresa), por lo que la labor de acopio de información se les facilita en mayor medida.

Ante tales condiciones, resulta claro que la cobertura noticiosa es una actividad de rutina, pero no por ello se encuentra programada ni planeada. No existe una estructura sistemática de acercamiento a las fuentes. En todo caso, los reporteros han interiorizado, una serie de criterios de noticiabilidad a partir de un intenso proceso de socialización con la organización a la que pertenecen y, a partir de estos criterios interiorizados contactan a diferentes funcionarios que son representantes de las fuentes informativas que tienen asignadas. Estos criterios también les sirven a los reporteros para articular temas sobre los cuales tratar en su acercamiento con estos actores.

La ronda por las fuentes, en conjunción con las exigencias organizacionales, ${ }^{4}$ obliga a los reporteros a adquirir ciertos grados de versatilidad en la interpretación de la cobertura. Como no

${ }^{4}$ Las exigencias organizacionales corresponden a una serie de condicionantes que impone la empresa y que los periodistas deben atender. En este caso, las exigencias más importantes son: una cuota noticial de cinco informes diarios para los reporteros de "Local", los cuales deben proceder de distintas fuentes legitimadas y tener un tamaño de 40 líneas; la entrega de sus notas redactadas por completo a las cinco de la tarde de cada día; el cumplimiento del proceso de "tiempos y movimientos" para la producción del diario en un ciclo noticioso de 24 horas, entre otras. 
hay un actor que dirija en lo operativo el acercamiento de los reporteros a la realidad noticiosa, entonces los reporteros tienen un margen un poco más amplio de decisión, aunque ésta siempre se encuentra enmarcada por los criterios organizacionales interiorizados. Un ejemplo de lo anterior se verifica con la reportera que cubre los colegios de profesionistas. En este sentido, no únicamente el presidente del Colegio de Contadores Públicos, por decir algo, es susceptible de configurarse como una fuente informativa, sino todos aquellos contadores que pertenezcan a la asociación y que ofrezcan declaraciones que cubran las expectativas de la organización periodística interiorizadas en la reportera, lo que permite que se extienda el panorama de cobertura.

\section{RutinAS DE TRATAMIENTO DE LA INFORMACIÓN}

La importancia de las rutinas de tratamiento de la información es fundamental porque, como resultado de ellas, la organización define cuáles de todos los informes entregados por los reporteros se convertirán efectivamente en noticias. Estas rutinas integran los procedimientos de selección, jerarquización y presentación de las noticias. Además, constituyen el factor de socialización principal a partir del cual los periodistas que laboran en el diario aprenden a distinguir los acontecimientos noticiables de los que no lo son. Esto se debe a que los criterios organizacionales para la selección noticiosa se interiorizan en los periodistas, y de esta manera se convierten en estructuras de interpretación acerca de la realidad. Cuando un reportero no ve publicadas sus noticias, debe aprender que ese tipo de reportes no son considerados noticiables por la empresa, y viceversa con las informaciones que sí se publican.

\section{Selección de las noticias}

Puesto que las rutinas de tratamiento de la información son valoraciones organizacionales que se hacen de las noticias, los editores (responsables directos de tales actividades) deben haber 
interiorizado fuertemente los criterios de la empresa. De esta manera, se evita la fuga de sentido. El control sobre estas valoraciones es ejercido personalmente por el director. Cada día el director selecciona y autoriza noticias; también da visto bueno al trabajo que los editores de las diferentes secciones realizan con respecto al tratamiento de la información bajo un sistema de toma de decisión autoritaria. La autoridad es la herramienta con la que el director coordina las actividades de tratamiento, y la estructura organizacional lo permite porque lo ubica como el gatekeeper más importante debido al lugar jerárquico que ocupa.

Tú llevas la materia prima, si bien es cierto no es harina, ya está cernido, ya está hecho, ya está pensado, pero de cualquier manera la forma que se le da a la información ya no es cosa de uno: uno la elabora pero, vamos, el enfoque o la trascendencia que el periódico le quiere dar ya no está en tus manos, o sea tú ya no la publicas, no le puedes decir al director: "¡esta nota es de primera plana!”, o "esta nota es para interiores", o "ésta es la de ocho y ésta me la mandan allá al cajón... de lo que no sirve ¿no?”, sino que tú diario traes tu información, es tu compromiso, y ahí está la información, ahí están las notas. Si el director o el periódico consideran que son buenas las ponen y si no pues no las ponen, y párale de contar. ${ }^{5}$

Al mismo tiempo, aceptar la autoridad del director les evita a los editores la necesidad de decidir cuál información es noticia y, por lo tanto, publicable. De tal manera, el control autoritario es a la vez sistema operativo para la decisión y estrategia operativa para la publicación "correcta" del periódico, porque le evita al editor decidir cuáles noticias son importantes, pasando tal responsabilidad a un nivel superior en la línea vertical de autoridad. Por lo tanto, la realidad reconstruida noticialmente necesita ser autorizada y seleccionada para ser presentada.

La selección noticiosa de la información inicia desde la asignación de fuentes a los reporteros, debido a que desde ese momento la organización define los ámbitos y los tiempos en los

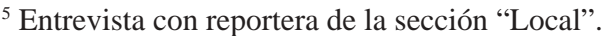


cuales las noticias ocurrirán. O por lo menos los ámbitos en donde se registra la información que interesa ser recopilada por el periódico. Los procedimientos para seleccionar y autorizar noticias no quedan aún claros, pero es evidente que se ponderan relaciones políticas y económicas por parte de los responsables de estas rutinas, ya que las fuentes informativas suelen ser administradoras de estos tipos de poder.

\section{Jerarquización de las noticias}

El formato periodístico para la presentación de las noticias conlleva ciertos valores propios de la actividad informativa. Los periodistas definen en cada edición la noticia más importante que ocupará el lugar denominado ocho columnas de la primera pla$n a$, y a partir de ahí se eslabonan las demás hasta tener formada la primera página del diario; después las ocho columnas de interiores y, finalmente, las demás noticias, que se utilizan casi como una manera de llenar el espacio disponible. En este proceso de nuevo aparece el director como el sujeto que define la jerarquía de las noticias gracias a su posibilidad de toma de decisión en la organización noticiosa.

Cuando los periodistas se refieren a la manera en la que se jerarquizan las noticias, utilizan la metáfora del "impacto social", según el cual valoran el grado de polémica e importancia (en ese orden) que la noticia puede tener en los públicos lectores. Esto da la pauta para señalar que en realidad este proceso implica la valoración de la nota mediante el reconocimiento de escenarios y fuerzas sociales, económicas y políticas.

Existen fuentes informativas que suelen ser consideradas "importantes" y que por lo regular se encuentran ligadas al poder político y económico. La jerarquización obliga a pensar la noticia desde antes de que sea elaborada; por esa causa la empresa periodística asigna a sus reporteros más "aptos" (más socializados en sus criterios organizacionales) a este tipo de fuentes. 


\section{Cabezas y titulares. La presentación de las noticias}

Si las noticias son una interpretación de la realidad por parte de los reporteros con mediación de los criterios organizacionales, las cabezas y titulares son nuevas interpretaciones que la organización hace de las noticias. Es pertinente analizar la lógica mediante la cual se elaboran, porque representan una propuesta de lectura (y por lo tanto de sentido) de las noticias.

El discurso periodístico acerca de los titulares se refiere a la esencia de la noticia. Redactar un encabezado es encontrar esa esencia y resaltarla. Pero lo que en realidad se resalta en las cabezas es lo noticiable del acontecimiento desde la visión de la empresa periodística. Por otro lado, el asunto es también una estrategia mercadológica porque los titulares resaltan elementos que la organización supone capturarán la atención de los lectores. Después de todo, destacar ciertos aspectos de las noticias mediante los titulares es una manera de hacer una oferta periodística frente a una demanda informativa.

En la construcción mercadológica o construcción noticial, las cabezas - al igual que las noticias - deben sujetarse a las condicionantes organizacionales. Día con día, el jefe de la sección "Local" debe presentar las cabezas al director del periódico para que sean autorizadas. El director decide cuáles de todas las cabezas presentadas "pasan”, a cuáles hay que practicarles algún cambio, o definitivamente cuáles deben ser cambiadas por completo. De nueva cuenta encontramos al director del diario como el filtro más alto en el proceso de tratamiento del material noticioso. La razón de ello es el cuidado institucional que la empresa le dedica a su producto más importante, las noticias. Se puede decir que es una especie de control de calidad simbólico altamente supervisado. 


\section{B) Las noticias en Aguascalientes: hacia UnA CARACTERIZACIÓN}

Las noticias son resultado de las prácticas que se realizan para elaborarlas. Estas prácticas se estructuran en forma de rutinas noticiosas, cuyo uso en este diario aguascalentense ya ha sido descrito en forma sintética. Pero además, estas acciones generan ciertas características en las noticias que es necesario señalar para entender cómo son construidas.

\section{LA NOTICIA ES PRODUCTO DE LA SOCIALIZACIÓN}

En gran medida, las habilidades necesarias para elaborar noticias se adquieren en un proceso de socialización complejo en donde diferentes actores se encuentran en una interacción continua. Puesto que el primer contexto de la producción noticial es la organización, es ahí donde el periodista inicia su proceso de aprendizaje noticioso. Este aprendizaje se encuentra definido por los criterios organizacionales que el sujeto debe interiorizar para ser considerado apto por parte de la empresa periodística.

La forma en la que el periodista aguascalentense se socializa está relacionada con las rutinas de selección y autorización de las noticias. Los reporteros del diario analizado se mantienen en una incertidumbre constante debido a que no saben a ciencia cierta si las informaciones que entregan cubren las expectativas noticiosas de la empresa, puesto que no cubren órdenes de trabajo ante la falta del jefe de información. De tal forma, es hasta el día siguiente, cuando ven su nota publicada (o no la ven), que salen de la duda. Esto ayuda a que los reporteros vayan identificando los temas, el tratamiento de la información y hasta las fuentes informativas, que son destacados por la organización y cuáles son minimizados o ignorados. De esta manera van interiorizando los criterios.

Otro elemento clave para la socialización noticiosa es el cumplimiento de las exigencias organizacionales. Cada reportero debe atender tales condicionantes empresariales y, en su trato con los 
colegas y con los pares, aprende a hacerlo. Por esa causa, las competencias que un periodista adquiere dependen en gran medida de la sección del periódico a la que pertenece, ya que en cada una de ellas la forma de construir noticias tiene sus especificidades.

\section{LA NOTICIA ES UNA LUCHA DE PODER}

La noticia es un espacio para la lucha de poder en diferentes planos. En el plano organizacional, jefes y reporteros forman dos bandos en donde los primeros representan la parte normativa de la construcción de noticias, y los segundos la operativa. Esto implica que los jefes y directivos sean quienes imponen los criterios organizacionales para la elaboración de noticias y los reporteros se ven en la necesidad de negociar constantemente esta concepción mediante diversas estrategias para que sus reportes sean aceptados como noticias.

Para los reporteros las noticias tienen un valor dinámico debido a que se enfrentan diariamente a la labor de narrar ciertos acontecimientos que se consideran noticiosos. Esto implica que los reporteros se aproximen a la realidad con una estructura de interpretación que han interiorizado organizacionalmente, pero que deben confrontar con el acontecer. Por otro lado, para los jefes y directivos la noticia tiene un valor de significación, debido a que ellos no se preocupan por la producción de los reportes noticiosos y más bien se enfocan al tratamiento de esos reportes.

Esta situación suscita en Aguascalientes una lucha mediante la negociación y el consenso por legitimar el discurso, unos por la necesidad de que sus reportes sean aceptados por la empresa, y los otros por sentar las normas bajo las cuales esos reportes deben ser construidos. Un elemento fundamental para el reportero cuando debe definir lo que es noticia, es que esa definición está en función de lo que la empresa dicta. De tal manera, la noticia no existe sin la empresa. Un acontecimiento noticiable sólo tiene ese valor en tanto que la empresa lo acepta como tal. Así, los reporteros deben buscar información que ellos juzguen que la empresa considerará adecuada. 
Las diferentes concepciones acerca de la noticia llevan a enfrentar a los reporteros, que argumentan la cuota noticial diaria, con los jefes, que exigen informaciones investigadas y trabajadas arduamente, en lugar de simples declaraciones. Por un lado, hay una exigencia normativa en el discurso para que los reporteros investiguen, pero existen condiciones concretas (la cuota, la hora de entrega, la certificación de las noticias en fuentes informativas) que impiden que esa exigencia se cumpla.

Si legitimar las noticias es el objetivo de la lucha del discurso, la cuota de noticias es el instrumento de esa lucha. A la vez, los reporteros culpan y se escudan en la cuota noticial para mantener la rutina de elaborar noticias mediante declaraciones de fuentes informativas, lo cual también permite evitar la necesidad de definir qué es noticia. Y la organización noticiosa también usa la cuota de noticias como una forma de controlar que en efecto se llenen los espacios necesarios para la publicación del día siguiente, sin importar si son declaraciones o investigaciones.

\section{LA NOTICIA ESTÁ EN LAS FUENTES}

El elemento principal que define la noticia en Aguascalientes es la fuente de la que procede. Existen fuentes informativas altamente legitimadas por la estructura social (por lo regular funcionarios públicos) que reciben cobertura en forma sistemática y cuyas actividades y declaraciones son noticiables en gran medida. Al grado que pueden ofrecer declaraciones noticiosas de asuntos que se encuentran fuera de su ámbito de acción y de quienes no son conocedores; independientemente de la pertinencia de sus señalamientos, el material es recogido por los reporteros y publicado por los diarios. Como ejemplos de este tipo de fuentes, se puede citar al gobernador del estado, el obispo de la diócesis, el alcalde de la capital, los diputados locales, etcétera. Por otro lado, las exigencias organizacionales y las reglas no escritas del periodismo obligan a los reporteros a acercarse a las fuentes socialmente legitimadas. De no hacerse así, la noticia será considerada ilegítima y no se publicará. Citar la fuente es fundamental. 
Los reporteros se acercan a las fuentes informativas mediante tres criterios específicos:

a) Informativo. Se refiere al valor informativo de la fuente en sí misma, por ubicarse en un punto alto dentro de la escala social y de su burocracia de adscripción, lo cual las legitima como tales.

b) Político. Ciertos actores con determinada legitimidad suelen convertirse en fuentes informativas frente a otros actores que no logran acceso a los medios noticiosos porque representan voces alternativas, disidentes y, por lo tanto, no legitimadas.

c) Comercial. El diario discrimina fuentes informativas debido a las relaciones comerciales que estos actores mantienen con el periódico. Por ejemplo, durante el acercamiento empírico se observó cómo el Partido del Trabajo no recibía cobertura porque no había cubierto el compromiso de pago de la publicidad contratada durante una campaña electoral pasada.

En Aguascalientes se corrobora el "criterio general de facticidad con el que actúa un periodista", en el que se establece que "algo es como es porque alguien lo dice" (Fishman 1983: 107).

\section{LA NOTICIA ESTÁ EN EL TEMA}

Para enfrentar las exigencias organizacionales, los reporteros igualan temas con noticias. Durante el trabajo de campo, el investigador fue testigo del proceso de traspaso de una reportera de la sección "Local" a la sección de "Sociales". Al enfrentar la cuota noticial, después de dos semanas, la reportera no era capaz de entregar las cinco notas diarias de rigor. El diálogo con los pares en su proceso de socialización le dio la solución: aprendió que en cada acercamiento a las fuentes informativas podía entrevistarlas acerca de diversos temas, y que cada tema es una nota potencial. Como el diario no acepta fuentes repetidas en las notas que un reportero entrega como resultado de un día de trabajo, entonces esas notas excedentes pueden ser guardadas para días difíciles, cuando no es posible encontrar la cantidad de notas exigidas. 
Las noticias pueden almacenarse durante varios días y de hecho así lo hacen los reporteros, para usarlas en los "días malos". Para un reportero, una entrevista no es igual a una noticia, sino a varias. Trabajar las notas de esta manera implica una organización mental del reportero desde el momento de plantear preguntas a las fuentes informativas. Así, el reportero articula preguntas de múltiples temas de acuerdo con las noticias que necesita obtener.

\section{LA NOTICIA ES UN RECURSO MERCADOLÓGICO}

Las noticias son la estrategia mediante la cual la empresa dirige la compra de ejemplares por parte de los lectores. Puesto que los medios de difusión venden públicos a los anunciantes (Sánchez Ruiz 1992: 85), las noticias se convierten en un recurso importante para ese complejo proceso de generación de utilidades a través de la publicidad, a la cual acompañan las noticias.

La sección "Local" del diario analizado abre normalmente ocho páginas, de las cuales entre 25 y $30 \%$ corresponde a publicidad (según datos otorgados por uno de los responsables de los espacios publicitarios en el medio). En caso de que la venta de publicidad se incremente, se abren nuevas planas en múltiplos de dos o de cuatro. Esto supone también la necesidad de más noticias que permitan cubrir el nuevo espacio disponible.

En cambio, si hay un excedente en la producción de noticias no se abren nuevas planas, sino que se jerarquizan y las menos importantes, que no alcanzan a publicarse, se dejan en reserva para cuando, como en el caso de la apertura de planas, se requiera llenar espacios.

\section{C) RELACIONES INTERPERSONALES EN LA PRODUCCIÓN DE NOTICIAS}

Una actividad fundamental que llevan a cabo los periodistas en el proceso de la construcción de noticias, es la de relacionarse con otros actores. De las características de esa relación dependerá, en 
gran medida, el tipo de noticias que elaboran, pues los reporteros deben contactar sujetos que poseen información noticiable además de negociar y consensar con sus colegas, jefes y directivos el sentido de las noticias.

En este estudio, en particular, se identificaron cuatro tipo de relaciones:

\section{Relaciones de los reporteros con sus jefes y directivos}

Los jefes y directivos se asocian con el aspecto normativo acerca del proceso de elaborar noticias, mientras que los reporteros son el aspecto operativo. La relación de los jefes con los reporteros es principalmente de desconfianza. Esto se debe a que los jefes ejercen un control sobre la producción de sentido que se hace de la realidad a partir de los reportes noticiosos para cuidar intereses políticos y económicos que deben ser ponderados al construir noticias. La principal muestra de desconfianza consiste en considerar que los reporteros mantienen intereses ideológicos o hasta económicos (por medio de regalos, embutes, etc.) con las fuentes informativas.

La desconfianza llega a tal nivel en esta empresa periodística, que los reporteros carecen de credenciales que los acrediten como trabajadores de la prensa, para evitar que abusen del poder social que este instrumento otorga y que no dañen, de esta manera, la imagen del diario.

Otro aspecto importante relacionado con la desconfianza es la valoración de las noticias en los procesos de tratamiento de la información. Los jefes creen que es posible averiguar si los reporteros mantienen intereses compartidos con sus fuentes gracias al tratamiento que le otorgan a las noticias que elaboran. Si lo detectan, las noticias no son publicadas. Esto incide en la socialización del reportero, que al no ver sus notas publicadas, deja de frecuentar la fuente informativa de donde proceden. 


\section{Relaciones de los reporteros con sus pares dentro de la organización}

Estas relaciones están enmarcadas por el apoyo y la solidaridad frente a las exigencias empresariales y por el celo profesional. Por lo tanto, este tipo de interacciones resultan un tanto contradictorias. Por un lado, los reporteros se apoyan entre sí compartiendo estrategias para cumplir con las condicionantes organizacionales. Sobre todo si se trata de reporteros novatos que se encuentran en pleno proceso de socialización, los compañeros los aconsejan sobre las maneras en las que pueden encontrar noticias de manera más fácil.

Por otro lado, cuando los reporteros acuden a sus coberturas, se mantienen al margen de las fuentes informativas que la organización no les ha asignado directamente. Esto tiene que ver con el celo profesional; cada reportero evita entrometerse en los ámbitos noticiales de sus compañeros, aun bajo el riesgo de perder una noticia importante. Los reporteros que acuden a eventos programados (ruedas de prensa, actos públicos, desayunos o comidas con funcionarios, etc.) suelen encontrar ciertos actores sociopolíticos que corresponden a las fuentes informativas de otros compañeros. Sin embargo, no las entrevistan aunque los colegas de otras organizaciones sí lo hagan. Violar esta regla no escrita implicaría entrar en problemas con el reportero de la fuente, quien parecería quedar mal con la organización periodística debido a que un compañero a quien no se le ha asignado la fuente recoge información que él no tiene.

\section{Relaciones de los reporteros con los colegas fuera de la organización}

Los ámbitos noticiales no sólo son lugares para recoger información, también son puntos de encuentro. En estos lugares los reporteros se reúnen con diversos actores que participan directa o indirectamente en la producción de noticias. Sobre todo, los re- 
porteros se encuentran con colegas que pertenecen a otros medios noticiosos y en cuya interacción se define en gran medida el carácter noticioso de las informaciones.

La interrelación entre los colegas va desde la solidaridad hasta el consenso y la negociación de las noticias. En lo que se refiere a la solidaridad, se puede observar que los reporteros comparten recursos (autos, celulares, grabadoras, libretas, grabaciones...) e información obtenida mediante entrevistas colectivas o eventos programados para la prensa. Estas prácticas solidarias tienen la finalidad de enfrentar sendas exigencias organizacionales y cada uno está dispuesto a colaborar porque sabe que puede llegar el momento en que él mismo necesite del apoyo de los demás para satisfacer las demandas del medio noticioso al que pertenece.

El otro aspecto, el de la negociación y el consenso de la información, tiene que ver con el carácter colectivo de ciertas informaciones noticiosas. Existen eventos programados para la prensa a los que acuden los reporteros de todos los medios noticiosos que han sido asignados a la fuente. La información vertida en tales actividades fácilmente puede ser compartida con colegas que no asistieron a ellas, la mayoría de las veces porque realizaban una cobertura en otro lugar a la misma hora.

En el caso de las entrevistas colectivas, en donde varios reporteros interrogan al mismo tiempo a una fuente informativa, los periodistas se reúnen al final para definir los puntos noticiosos de la declaración y programar la entrega de los mismos en sus respectivas organizaciones de adscripción. Esto permitirá a los reporteros presentar diversas noticias obtenidas en la entrevista de manera dosificada en distintas entregas (porque los medios aguascalentenses no aceptan más de una noticia referida a la misma fuente durante un solo día) con la confianza de que la información no será "quemada". 6

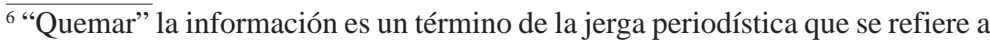
la información que un reportero guarda para escribir una noticia en una ocasión posterior, pero que, antes de hacerlo, otro medio noticioso la publica. Esa noticia ya está "quemada" y ya no podrá ser usada por el reportero que la guardaba. 


\section{Relaciones de los reporteros con las fuentes informativas}

$\mathrm{El}$ asunto de las relaciones entre los periodistas y las fuentes informativas es de los más complejos y problemáticos de tratar. A tal grado, que incluso hay quienes proponen que el enfoque de la sociología del periodismo centrada en las fuentes informativas, merece ser planteada como una subárea de esta perspectiva teórica ( $c f$. Schlesinger 1992; McNair 1998), sobre todo debido a las estrategias que las fuentes realizan con la finalidad de recibir cobertura por parte de los medios noticiosos.

La importancia de la relación entre los reporteros y las fuentes informativas es fundamental. Esto se debe a que en gran medida las noticias son resultado de las estrategias sistemáticas de acercamiento que los periodistas mantienen con las fuentes informativas para obtener noticias. De hecho, para que un periodista posicione sus reportes como noticias, es indispensable que procedan de una fuente informativa legitimada.

En general, la relación entre estos dos actores en Aguascalientes es cordial y armónica. Esto se debe a que ambos comparten intereses en el proceso de la cobertura noticiosa. La fuente desea aparecer en los medios noticioso porque eso le da presencia en el espacio público, mientras que los reporteros se benefician al obtener información que requieren para satisfacer las necesidades de su medio noticioso.

En esta interrelación simbiótica, las fuentes ponen todo de su parte para recibir cobertura porque tienen la encomienda de la burocracia a la que pertenecen de lograr el acceso a los medios. Las fuentes que tienen los recursos necesarios y que han establecido estrategias profesionales de acercamiento a las organizaciones periodísticas a través de las relaciones públicas (que son muy pocas), otorgan todo tipo de ayuda a los reporteros, como el acceso a equipo de cómputo, material diverso y soportes informativos (boletines, versiones estenográficas, informes, etc.). Sin embargo, la mayoría de las veces el único apoyo que las fuentes pueden otorgar a los reporteros (porque la mayor parte de las fuentes in- 
formativas aguascalentenses carecen de la infraestructura adecuada) es disposición e información, lo cual es más que suficiente.

Los reporteros negocian información con sus fuentes mediante un proceso que consiste en empatizar. Las fuentes otorgan información a los reporteros para recibir cobertura, pero hay informaciones que las fuentes no desean que se publiquen. Los reporteros deben negociar con sus fuentes para poder transformar en noticias la información que obtienen. Lo hacen para no violentar el vínculo que han construido con quien cotidianamente les otorga información.

El motivo por el cual una fuente no desea publicar cierta información puede tener diferentes lecturas: evitar compromisos, no afectar otros procesos a los que se están refiriendo en declaraciones, etc. En varias ocasiones se pudo verificar cómo las fuentes piden en forma recurrente a los reporteros que no publiquen ciertos aspectos de una información, y los reporteros atienden esas peticiones. Este tipo de solicitaciones que realizan las fuentes es más claro en el caso de los reporteros policiacos. Las fuerzas de seguridad continuamente están pidiendo a los reporteros que no manejen tal o cual información, pues (de acuerdo con el discurso de las autoridades) el riesgo de hacerlo es poner sobre aviso a los delincuentes. Los reporteros suelen aceptar el razonamiento y guardan información que ya tienen, esperando que la fuente les dé autorización para publicarla. El ejercicio periodístico basa muchas de sus prácticas en la lealtad.

A final de cuentas, el encuentro entre los reporteros y las fuentes informativas es el encuentro de dos burocracias. Cada sujeto individual ha interiorizado los criterios y las lógicas de su burocracia de adscripción y actúa de acuerdo con ellas; uno con la encomienda de lograr el acceso a los medios noticiosos y el otro con la exigencia de encontrar información certificada que pueda convertirse en noticia. De esta manera se genera un tercer espacio, que es precisamente el de la interacción entre estos dos actores y que se materializa en la producción de noticias. 


\section{Poder de decisión frente a las determinaciones organizacionales}

Puesto que las noticias son el resultado de procesos sociales y no de decisiones individuales, y que las exigencias de la organización llegan incluso a determinar ciertos aspectos de las relaciones interpersonales, ¿qué sucede con el poder de decisión del individuo en este complejo sistema de producción de mensajes informativos?

En el proceso de producción noticiosa aguascalentense es posible observar que la toma de decisión se relaciona con los criterios organizacionales que cada sujeto ha interiorizado. Estos criterios ofrecen un margen de acción dentro del cual los trabajadores de la prensa consensan, negocian y deciden las noticias. Se encuentran en el centro de un control social complejo y cerrado. Cuanto más arriba se encuentran los sujetos en la escala jerárquica (línea vertical de autoridad) de la empresa informativa, el margen de acción para la decisión se reduce, ya que el puesto que un periodista ocupa en la organización está directamente relacionado con el carácter normativo de las rutinas noticiosas. Quizás quien tiene el margen más amplio de decisión es el director del diario en tanto que se ubica como el gatekeeper más importante en el proceso y define los lineamientos (tal vez también determinado por los propietarios, las influencias supraorganizacionales y representaciones sociales acerca del periodismo) bajo los cuales se elaboran las noticias.

El reportero tiene que tomar decisiones, pero con la mediación de la empresa noticiosa y sus criterios. En la siguiente referencia empírica se muestra un ejemplo de la manera en la que un reportero determina la forma en la que dirige su atención a acontecimientos noticiables, con una clara mediación por parte de la organización noticiosa:

Hay veces que a ti te parece muy importante dar a conocer algo, y dices: "esto es importante y es un problema social" y te topas con que para la empresa no lo es. O sea, $[\ldots]$ de repente (sufres) un 
choque ¿no?, porque cada quien tenemos una percepción diferente de las cosas que nos rodean, entonces si te encuentras con eso, con que a lo mejor a ti te parece algo muy importante y a la empresa no [...] Tú llegas a lo mejor con otras expectativas, pensando otras cosas, y te vas dando cuenta del sistema de ahí del periódico, [...] les gusta este tipo de cosas, o este tipo de cosas mejor no las toco mucho porque me las van a hacer a un lado, entonces, por ahí te tienes que ir. Sí hay la libertad, porque luego dicen: "entonces ¿sí hay censura o no hay censura?", pues en realidad a veces hay mucha autocensura de nosotros mismos, pero pues a lo mejor porque yo ya sé que si ataco a cierta gente, pues no va a pasar, no se va a publicar, no va a pasar nada con eso, entonces, tú mismo ya vas escribiendo lo que sabes que también a la empresa le va a gustar y que la empresa considera pertinente darlo a conocer. ${ }^{7}$

Las decisiones sobre lo que se cubre y lo que no se cubre son tomadas por el reportero en el momento y en el lugar de la cobertura, pero no es una decisión personal, sino una decisión aceptada, interiorizada y reproducida desde la organización y sus valores noticiosos en el reportero. Es la manera en la que la empresa periodística ejerce el control social sobre los reporteros, principalmente para evitar la fuga de sentido no sancionado por la propia organización en el reporte de los acontecimientos noticiosos.

\section{D) VALORES NOTICIOSOS E IDEOLOGÍA PROFESIONAL \\ 1. Noticiabilidad de los reportes del acontecer}

Frente al acontecer, los periodistas se ven en la necesidad de realizar ciertas valoraciones para definir aquellos acontecimientos que tienen las características suficientes para convertirse en noticias, es decir, que son "noticiables". Desde la sociología del periodismo se han construido categorías para su análisis bajo el nombre de valores noticiosos. En este estudio se encontró que algunas valoraciones que influyen para dotar de noticiabilidad a ciertos acontecimientos tienen que ver con los siguientes elementos:

$\overline{{ }^{7} \text { Entrevista }}$ con reportera de la sección de "Local”, 19 de mayo de 2000. 


\section{Notoriedad de la fuente informativa}

Las instituciones que se encuentran más legitimadas en la estructura social suelen ser consideradas como fuentes de información periodística. El acceso a los medios opera mediante la legitimación. En Aguascalientes existen actores sociopolíticos adscritos a tales instituciones que sistemáticamente reciben cobertura de los medios de comunicación. La fuente de la que procede la información es el elemento más importante para dotarla de noticiabilidad. Incluso, se puede observar que gran parte de las veces las fuentes trascienden los temas de los que tratan las noticias, y estos actores pueden llegar a realizar declaraciones ante la prensa acerca de temas que se encuentran fuera de su ámbito de acción; por ejemplo, el obispo de la diócesis que se manifestaba con respecto a los procesos políticos, o el presidente de la asociación de abarroteros que presentaba su postura con relación a la construcción del sistema de tren ligero intermunicipal proyectado para el tránsito rápido de obreros y trabajadores de la construcción hacia la ciudad capital, procedentes de los municipios del interior del estado. ${ }^{8} \mathrm{Si}$ Fishman señalaba que los funcionarios representantes de las fuentes se constituyen en "conocedores oficiales de la realidad" (1983: 108), en Aguascalientes se puede observar que las fuentes no necesitan ser "conocedores oficiales" de algún ámbito en específico para poder hablar noticiosamente sobre él.

La legitimidad de la fuente informativa en tanto que ofrece información certificada por una burocracia, es sumamente impor-

${ }^{8}$ Durante el periodo de observación, uno de los temas que arrancó declaraciones de distintos tipos de fuentes (independientemente de su burocracia de adscripción) fue la construcción de este tren ligero. Todavía en la administración zedillista el proyecto fue presentado por el gobierno del estado y autorizado por la Federación. Esta situación fue criticada por varios grupos sociopolíticos y la discusión pasó a los medios noticiosos argumentando que se estaba desmotivando el trabajo agrícola y fortaleciendo la migración del campo a la ciudad en beneficio de las industrias emplazadas en la entidad. A la fecha el proyecto se encuentra detenido y el tema ha abandonado la agenda noticiosa local. 
tante; por ejemplo, cuando una asociación de enfermos renales protestó mediante una manifestación en las instalaciones del IMSS (Instituto Mexicano del Seguro Social) porque las sesiones de diálisis iban a dejar de ser semanales para ser quincenales, los representantes de esta institución de salud deslegitimaron a los manifestantes usando información filtrada ${ }^{9}$ (no oficial) entre los reporteros, quienes tomaron partido por los representantes del IMSS a quienes les otorgaron mayor credibilidad. La estrategia usada por el IMSs fue aprovechar la presencia de los medios que dieron cobertura a la protesta, para anunciar que no sólo se iban a mantener las sesiones semanales, sino que se habían comprado nuevas máquinas de hemodiálisis con lo que muchos pacientes renales iban a ser beneficiados. Con esta acción, la legitimidad de la institución se anotó un punto más frente a los medios noticiosos.

Los periodistas aguascalentenses otorgan distintos niveles de notoriedad a las fuentes informativas de acuerdo con dos criterios principales: a) institucionalización; mientras más legitimada se encuentre una fuente informativa por la institucionalización social, es probable que los periodistas le presten mayor atención, y b) actualidad; existen ciertas fuentes noticiosas que aparecen en los medios locales en función de la temporada (cobertura cíclica), como la agencia de protección civil en épocas de lluvias, cuando puede haber inundaciones; el sector salud en invierno, cuando se incrementan las enfermedades respiratorias; o la procuraduría de protección al consumidor en las fiestas decembrinas, cuando se vigila que los prestadores de servicios no se excedan en los precios y tarifas.

${ }^{9}$ La información filtrada a la prensa por parte de médicos que son "buena onda", según señalaron los reporteros, fue que el dirigente del grupo inconforme recibía comisiones por la venta de máquinas para diálisis, y que usaba a los enfermos para presionar a la compra de equipo con el respectivo beneficio personal. Esa versión no pudo ser verificada. 


\section{Notoriedad del tema}

Los reporteros igualan temas a noticias (la noticia está en el tema) con la finalidad de obtener reportes informativos noticiables en sus acercamientos con las fuentes. La organización noticiosa determina en gran medida la elección y tratamiento de los temas mediante la asignación de fuentes informativas a los reporteros. En el caso del periódico analizado, la falta de jefe de información que organice la cobertura diaria es un factor fundamental para establecer la dinámica de la cobertura y los temas que serán abordados en la interacción con las fuentes. Cada reportero tiene asignadas determinadas fuentes informativas; cada una de ellas, a su vez, tiene una especificidad propia que le permite al reportero abordar ciertos temas de una manera particular.

Además de los acercamientos con las fuentes, en un proceso complejo de consenso y negociación con los pares, colegas y jefes, con mediación de los criterios organizacionales, los reporteros contribuyen a que la empresa noticiosa vaya construyendo una agenda temática local. ${ }^{10}$ Los temas a los que la empresa noticiosa les otorga notoriedad parecen fundarse en una interrelación compleja de sujetos individuales e institucionales a partir de la cual se define el contenido de las noticias. A su vez, estos temas parecen responder a una valoración de fuerzas políticas y escenarios posibles que la organización realiza al seleccionar los temas noticiosos, de tal manera que quienes administran el poder político y el poder económico en Aguascalientes, de alguna manera influyen (mediante la cobertura que reciben por parte de las organizaciones de medios) para colocar ciertos temas en las consideraciones de las empresas periodísticas. En el caso del diario analizado, la asignación de fuentes otorgadas a los reporteros es un factor importante para definir el tipo de temas que pueden tratar en sus coberturas.

${ }^{10}$ Esta indicación no pretende incluirse dentro de los postulados de la Agenda Setting, sino que trata de identificar cómo es que las noticias enfocan temas específicos como resultado de un proceso de interacción entre diversos actores sociales. 


\section{Proximidad}

Para los periodistas aguascalentenses es claro que la sección "Local" del periódico es la más importante. La organización distribuye a su cuerpo de reporteros utilizando a la ciudad como circunscripción. Esta situación excluye a los municipios del interior del estado y a la región circunvecina de la cobertura noticiosa y, por lo tanto, del interés de la organización periodística.

\section{Exclusividad}

Gran parte de las noticias entregadas por los reporteros que pertenecen al diario en donde se realizó el estudio, son "exclusivas". La carencia de un jefe de información es uno de los motivos por los cuales esto es así, situación que lleva a los reporteros a concertar citas con las fuentes cotidianamente ante la falta de órdenes de cobertura. En estas reuniones privadas los periodistas pueden obtener información inédita.

Sin embargo, la exclusividad de la información no necesariamente le concede noticiabilidad a los reportes, pues las notas exclusivas pueden ser usadas a discreción por parte del periódico para publicarse "cuando sea necesario", es decir, cuando se requiera llenar espacios. Las exclusivas "aguantan", dicen los periodistas, frente a las notas colectivas, que son más noticiables en el sentido de que su carácter colectivo obliga a publicarlas inmediatamente para evitar que se "quemen".

Por otro lado, los periodistas suelen expresarse de la exclusividad en términos de competencia. En el marco de la competencia empresarial, las reglas no escritas del periodismo fundadas en el celo profesional obligan a los reporteros a buscar las exclusivas, con lo cual demuestran el manejo de la fuente informativa y contribuyen a mejorar la imagen de su organización, que tiene la posibilidad de presentar noticias que otros medios no tienen. 


\section{Objetividad}

La objetividad es uno de los valores noticiosos principales. Sin embargo, contrario a su espíritu (fidelidad a la realidad), el formato bajo el cual la organización periodística exige a los reporteros presentar la información implica la evaluación y la jerarquización de los datos. Parece que es un asunto técnico de redacción, pero implica mucho más que eso. Se trata de que el reportero debe resignificar la información primaria con la que tuvo contacto para poder ofrecer una narración acerca de la realidad (reconstruirla). Sólo que esta realidad resignificada cobra una nueva distinción: ¡es noticia!

Desde el momento en que el reportero se ve obligado a verbalizar su experiencia (ya se trate de una interacción con otro sujeto, como es el caso de una entrevista, o de la interacción con el acontecer en una cobertura), y además de hacerlo de acuerdo con una estructura convencional para la presentación de una noticia, está ejerciendo un acto de interpretación de la realidad y, por lo tanto, alejándose de la pretendida objetividad.

El discurso principal acerca de la objetividad gira alrededor de la honradez. El reportero pretende ser veraz en sus informaciones para alcanzar objetivos múltiples: a) ganar credibilidad del público lector; b) demostrar profesionalismo a sus fuentes informativas para no perderlas, y c) evitar ser acusado de tendenciosidad (Tuchman 1983: 96). Además, se libera de la responsabilidad social (e incluso judicial) de la información noticiosa que entrega.

Como el lenguaje a partir del cual el periodista expresa la realidad es una acción subjetiva, entonces tiene que apelar a una estrategia: para evitar problemas, que lo diga otro. En este sentido, llama la atención cómo la grabadora pasa, de ser un implemento tecnológico para el registro de entrevistas, a un testigo eficiente que protege al redactor y a la organización periodística de problemas ocasionados por declaraciones comprometedoras. Ésta es la razón por la cual el periodismo objetivo exige a los reporteros el acercamiento a fuentes legitimadas y burocratizadas para la recopilación de información. 


\section{IDEOLOGÍA PROFESIONAL DE LOS PERIODISTAS}

Los procesos de socialización en las rutinas periodísticas y sus valores, permiten que los periodistas interioricen estructuras de interpretación de la realidad por medio de las cuales se aproximan a ciertos aspectos del acontecer, para transformarlo en noticias. Esta situación implica la construcción de una ideología periodística que incide en la labor cotidiana de elaborar noticias. A partir de esta ideología, los periodistas se representan a sí mismos y a su profesión en el marco de la sociedad a la que pertenecen. Para este acercamiento a la ideología profesional se tomaron en cuenta los siguientes elementos: la vocación, la profesionalización de los periodistas y las funciones sociales del periodismo.

\section{Vocación}

El periodismo es un oficio que se adquiere con la práctica diaria. Ante la incertidumbre que genera el trabajo del acercamiento diario al acontecer, los periodistas en Aguascalientes utilizan metáforas para referirse a la labor que desempeñan. Tener vocación de periodistas involucra una serie de capacidades, como el desarrollo del "olfato periodístico", es decir, "saber encontrar noticias en donde parece que no las hay".

La consideración de la vocación periodística atraviesa por la autopercepción. La gente de prensa se percibe a sí misma como sujetos determinados por múltiples circunstancias, tales como el tiempo (siempre situados en el pasado, tienen que escribir "ayer" cuando aún es "hoy", lo que implica desfasamiento y presión por cumplir en tiempo), las condicionantes organizacionales, el acceso a la información, etcétera.

De todas estas determinaciones, lo que sobresale son las exigencias de la organización. Adquirir oficio, tener olfato periodístico, o tener vocación, son frases que los periodistas utilizan para referirse a la capacidad que deben desarrollar mediante los procesos de socialización para satisfacer las expectativas de la organi- 
zación implícitas en sus exigencias. Esto lleva a señalar que los periodistas se definen a sí mismos —en última instancia- como entes organizacionales, porque encuentran en la organización periodística la razón de ser de la actividad que realizan:

En seguida, debes de tener [...] ;el olfato!, el famoso "olfato periodístico", que nadie sabe qué es, de dónde viene, cómo llega, pero bueno, es como una inspiración, es algo que te llega y que dices esto es una noticia: "esto es un notición, ¡chin!, esto es un notición, sé que va a impactar". Y lo llevas al periódico y lo escribes con mucha fe, y lo escribes con mucha entrega, lo escribes con emoción y lo dejas. Y al día siguiente buscas la edición y la lees, y te das cuenta de que sí era la noticia, que sí era el notición. O bien, que ni siquiera te la publicaron, también. Que tú sentiste, que a ti te dio la corazonada, pero, bueno, a veces hay corazonadas falsas, también, como en todo ¿no? Y ya también hay criterios más arriba, en las jerarquías del periódico que determinan ¿no?, esto sí es noticia, esto no; o bien, esto no lo vamos a publicar, ¿por qué?, por lo que cada quien allá arriba decida ¿no? ${ }^{11}$

\section{Profesionalización del periodista}

Mediante el trabajo de campo pudo verificarse que en Aguascalientes existe una gran rotación de personal entre las empresas noticiosas. Basta el ejemplo de la sección de "Sociales" del diario analizado para dar cuenta del movimiento de los recursos humanos durante poco más de un año de observación. Al final de ese periodo, la plantilla de reporteras de esa sección se había renovado por completo. Una de las posibles razones es que, al ser una ciudad pequeña en donde existen tres carreras profesionales de comunicación con egreso anual, esta situación ha contribuido a colocar a los comunicadores en las dinámicas del mercado. De tal manera, los medios noticiosos pueden echar mano de personal capacitado cuando lo requieran, porque su demanda de periodistas se encuentra parcialmente resuelta.

$\overline{{ }^{11} \text { Entrevista }}$ con reportero de la sección "Local". 
Sin embargo, subsiste la idea de que la formación universitaria no es suficiente (más bien es considerada insuficiente y desvinculada del verdadero trabajo periodístico) y los egresados universitarios inexpertos se integran a las empresas noticiosas en donde pasan por un proceso fundamental para convertirse en periodistas: la socialización. La brecha que separa al periodista empírico, formado en el fragor de la batalla diaria por la búsqueda de la nota, del reportero universitario poseedor de un título y de gran inexperiencia, es la socialización en el medio noticioso.

La creación de carreras de comunicación y periodismo en realidad se basa en el punto cúlmine de institucionalización de las prácticas periodísticas, al grado de convertir ese conjunto de competencias en una licenciatura profesional. De hecho, la incursión en los medios noticiosos de los periodistas formados en las universidades es parte de las nuevas prácticas periodísticas ligadas a las nuevas tecnologías y a las nuevas posibilidades de acción en el terreno de la recopilación de la información para notificaciones periodísticas. Los directivos de los medios noticiosos han abierto el acceso a los jóvenes universitarios por diferentes razones: el uso de computadoras, la necesidad de cubrir la gran movilidad de personal en las empresas periodísticas locales con personal capacitado, las prácticas periodísticas en medios electrónicos, donde los reporteros antiguos no están socializados y cuyos ciclos noticiosos son más inmediatos, etcétera.

Asimismo, la profesionalización de los periodistas ha obligado a la profesionalización de las fuentes informativas en el acceso a los medios de comunicación a través de las "relaciones públicas". Es así que determinadas fuentes, con la estructura y los recursos suficientes para ello, han integrado oficinas de "comunicación social" en donde mantienen a profesionales del periodismo y las relaciones públicas con la finalidad de lograr el acceso a la prensa. ${ }^{12}$

${ }^{12}$ Este tipo de prácticas han sido desarrolladas tanto en instituciones públicas como en privadas que se han legitimado como fuentes informativas de los medios. Ejemplos de fuentes del sector público con este tipo de estrategias son el gobierno del estado, el gobierno municipal o el Congreso local. Un 
La formación de los nuevos periodistas en las universidades, la profesionalización de las relaciones públicas y el uso de nuevas tecnologías, entre otras cosas, se manifiestan a la vista de los reporteros de la vieja guardia como nuevas prácticas para recopilar información, que no se veían antes. El valor de la noticia se asocia pues a las dinámicas con las que el reportero debe enfrentarse. En un mundo donde los canales rutinarios de información cada vez son más profesionalizados y automatizados (por ejemplo, ahora los boletines de prensa se pueden enviar por fax o por Internet), los reporteros deben responder a la altura de las circunstancias, modificando sus prácticas periodísticas.

\section{Funciones sociales del periodismo}

Hablar de las funciones del periodismo, por antonomasia, es hablar de las funciones de quien lo ejerce. La importancia de articular las funciones que los periodistas le otorgan a su labor radica en la posibilidad de identificar el sentido que le dan al periodismo frente a la sociedad, en donde existe una gama de profesiones diversas (cada una con su función propia), con cuyos practicantes los periodistas han tenido, tienen o tendrán contacto. Es así que los periodistas se vinculan diariamente con expertos, técnicos, académicos, analistas, políticos, etc., de donde obtienen información que traducirán en noticias.

La intermediación. Una de las funciones principales es la intermediación, por medio de la cual los periodistas se identifican a sí mismos como los mediadores entre diferentes sectores de la sociedad: entre gobernantes y gobernados, empresarios y trabajadores, políticos y votantes, etcétera. Los periodistas se consideran como representantes del pueblo, de la "opinión pública", cuando en realidad son representantes de la empresa a la que pertenecen frente a otro tipo de actores como los gobernantes, quienes han sido electos por voto popular. ${ }^{13}$

ejemplo de fuente informativa del sector privado con oficina de relaciones públicas es la Concesionaria de Aguas de Aguascalientes (CAASA).

${ }^{13}$ El problema de la representatividad de los funcionarios públicos elegidos popularmente frente a la posible representatividad que puedan alcanzar los pe- 
Libertades individuales y colectivas. La libertad de expresión es el punto de confluencia entre la práctica periodística y los valores sociales mayores como la democracia, el desarrollo, la paz, etc. Esta libertad es articulada en el discurso de los periodistas en dos niveles:

a) La libertad de expresión (individual). Define la posibilidad expresiva del reportero con respecto a los temas que trata en sus informes noticiosos, y la defensa de esta garantía (por lo menos en el discurso) es fundamental para el ejercicio de la profesión. Llama la atención la manera en la que los reporteros aguascalentenses insisten en que sus noticias no son objeto de censura, aun cuando diariamente varias de ellas no son publicadas debido a los criterios organizacionales mediante los cuales son valoradas. Las explicaciones ligadas a las rutinas de tratamiento de la información permiten otorgar sentido a esas omisiones: no hubo espacio, están archivadas para publicarse después, etc. Las exigencias organizacionales establecen hasta qué punto los reporteros pueden practicar su libertad de expresión.

Sí hay la libertad, porque luego dicen: "entonces sí hay censura o no hay censura", pues en realidad a veces hay mucha autocensura de nosotros mismos, pero pues a lo mejor porque yo ya sé que si ataco a cierta gente, pues no va a pasar, no se va a publicar, no va a pasar nada con eso, entonces, tú misma ya vas escribiendo lo que sabes que también a la empresa le va a gustar y que la empresa considera pertinente darlo a conocer. ${ }^{14}$

riodistas respecto a sus lectores, no es objeto de esta investigación. En todo caso, el comentario pretende dar cuenta de un fenómeno de representación social que los periodistas aguascalentenses realizan con respecto a su propio trabajo. La cuestión de la representatividad, sin embargo, me parece importante y ofrece una veta de indagación con respecto a la interacción que los periodistas establecen con la estructura social (misma a la cual pertenecen). Tampoco es ignorado el hecho de que existen un sinnúmero de funcionarios que no son electos pero sí constituyen fuentes informativas; en todo caso pertenecen a un estado cuyos dirigentes principales sí han sido designados mediante comicios.

${ }^{14}$ Entrevista con reportera de la sección "Local". 
b) La libertad de prensa (colectiva). Los periodistas consideran que la libertad de expresión ejercida por la organización (libertad de prensa) es la garantía de que la "opinión pública" ${ }^{15}$ será expresada en las páginas del diario. Esto se conecta directamente con la oposición discursiva prensa-estado: los periodistas son actores legitimados para vigilar y cuestionar las acciones de los gobernantes, de quienes exigen las condiciones necesarias para que esta libertad no sea cooptada.

Ambas, la libertad de expresión (individual) y la libertad de prensa (colectiva), son constructos necesarios en la labor cotidiana de producir noticias, porque otorgan un marco de sentido a la utilidad y significación de los reportes periodísticos en el contexto de las funciones sociales del periodismo. Mediante estas estrategias, los reporteros y las organizaciones periodísticas legitiman los temas noticiosos y se invisten a sí mismos con la capacidad de contribuir a la generación de opinión pública y, por lo tanto, a la construcción de la democracia que sintetiza todos los valores sociales a los que se aspira.

\section{E) Conclusión}

Queda claro que el objetivo primordial de las acciones realizadas por las organizaciones noticiosas tienden a la socialización de los periodistas que laboran en ellas, con lo que se asegura que interiorizarán los criterios a partir de los cuales se espera que interpreten la realidad para construir noticias.

Las rutinas de producción noticiosa sintetizan estructuras de interpretación y socialización que los periodistas deben adquirir y después reproducir. Tales estructuras se legitiman al ser aceptadas por los propios hombres de prensa como las formas "correctas" de elaboración de las noticias. Esto quiere decir que las noticias son resultado de un proceso de significación de la realidad a partir de

$\overline{15}$ En este caso, "opinión pública" es considerada por los periodistas como la "opinión del pueblo", de la cual se consideran defensores. 
lógicas que los actores deben aceptar para elaborarlas, porque son impuestas organizacionalmente.

La noticias son significaciones acerca del entorno mediadas por múltiples actores institucionales (burocracias de adscripción, organización periodística) e individuales (reporteros, jefes, directivos, representantes de las fuentes de información) y determinadas por las acciones que esos actores llevan a cabo entre sí para generarlas y narrar la realidad.

La manera en la que las noticias son construidas, además, permite observar la constitución, legitimidad e ideología de la estructura social en la que los medios noticiosos aguascalentenses están inscritos. Si retomamos la metáfora de la red de fuentes noticiosas (Tuchman 1983: 36), se puede observar que los medios noticiosos locales organizan y programan la ocurrencia de las noticias mediante la asignación de fuentes a los reporteros, situación que permite identificar qué tipo de actores sociales están legitimados socialmente para ofrecer opiniones y señalamientos con respecto a determinados procesos que la sociedad experimenta. Esto implica que ciertas voces sean privilegiadas por los medios noticiosos y que otras sean ignoradas. La estructura social es reproducida y, a la vez, se encuentra implícita en las prácticas periodísticas.

El acercamiento de los reporteros a los "funcionarios-fuentes informativas", representa la confluencia de dos burocracias complejas, cada una con sus lógicas propias interiorizadas en sus representantes, quienes cumplen papeles que se complementan: el reportero tiene la obligación de encontrar, dentro de los tiempos marcados por la organización periodística, información certificada; por otro lado, el funcionario tiene la encomienda de lograr el acceso a los medios porque ello representa la posibilidad de destacarse y colocar su discurso en la estructura social.

Debido a todo esto, es necesario afirmar que las noticias no son la realidad, sino que la representan, son un recuento de ella (Hernández 1992: 237). Son narraciones, reconstrucciones del acontecer hechas a partir de procesos complejos de socialización, 
negociación, consenso y lógicas institucionales mediante los cuales los periodistas otorgan significado a la realidad.

En consecuencia, la presentada por los medios noticiosos aguascalentenses es una realidad fragmentada, oficial y delimitada. Es fragmentada porque los medios conceptualizan la actividad periodística como el reporte de acontecimientos que se llevan a cabo en ciertas partes, pero en otras no; cada ámbito noticial tiene sus propias características y en la cobertura periodística se encuentran, por lo regular, desvinculados. Es oficial porque las noticias se consensan en tanto que una fuente informativa legitimada por la estructura social emite declaraciones que son recogidas por las organizaciones noticiosas, mientras que otras voces alternativas carecen de acceso a los medios y, por lo tanto, a la realidad periodística. Es delimitada porque, gracias a la institucionalización de ciertas prácticas rutinarias, es posible que los acontecimientos noticiosos sean programados y que tengan espacialidades y temporalidades concretas para su ocurrencia.

\section{REFERENCIAS BIBLIOGRÁFICAS}

Agudelo Builes, Irene (1996) "La influencia de las rutinas productivas en la construcción del acontecer nacional. El caso de Siglo 21, periódico de Guadalajara, México", Comunicación y Sociedad, núm. 28. Guadalajara: DECsUniversidad de Guadalajara.

Bennet, Lance, A. Lynne Gressett, y William Haltom (1985) "Repairing the news: a case study of the news paradigm", Journal of Communication, vol. 35 , núm. 2, EUA.

BERKOwITZ, Dan (1992) "Non-routine news and news work: exploring a what-astory", Journal of Communication, vol. 42, núm. 1, EUA.

Borrego E., Salvador (1984) Periodismo trascendente, México.

Cervantes Barba, Cecilia (1994) "Análisis de contenido y etnografía en el estudio de la producción de noticias", en Cervantes Barba y Sánchez Ruiz (coords.), Investigar la comunicación. Propuestas iberoamericanas. Guadalajara: ALAIC/Universidad de Guadalajara.

- (1995-1996) "Valores noticiosos en el periodismo televisivo de nota roja. Bœsqueda articulada de indicadores empíricos", Comunicación y Sociedad, núm. 25-26. Guadalajara: DECs-Universidad de Guadalajara. 
(1995a) “De qué se construye el habitus en la práctica periodística?”, Comunicación y Sociedad, núm. 24. DECs-Universidad de Guadalajara.

_ (1996) "Construcción primaria del acontecer y planeación de la cobertura informativa. Propuesta metodológica para su estudio", Comunicación y Sociedad, núm. 28. DECs-Universidad de Guadalajara.

(2000) "Para superar la ruta de modelos, efectos y metáforas equívocas en la Sociología del Periodismo", en Orozco Gómez (coord.) Lo viejo y lo nuevo. Investigar la comunicación en el siglo XXI. Madrid: Ediciones de la Torre. CHомsкy, Daniel (1999) "The mechanisms of management control at the New York Times", Media, Culture \& Society, vol. 21, núm. 5. Nueva York: Sage Publications.

DAvis, Howard H., Philip Hammond, y Lilia Nizamova (1998) "Changing identities and practices in post-soviet journalism: the case of Tatarstan", European Journal of Communication, vol. 13, núm. 1, Reino Unido.

Diмміск, John, y Philip Coit (1983) "Levels of analysis in mass media decision making. A taxonomy, research strategy and illustrative data analysis", Mass Communication Review Yearbook, vol. 4. Beverly Hills: Sage, pp. 361-389.

Esser, Frank (1998) "Editorial structures and work in British and German newsroom", European Journal of Communication, vol. 13, núm. 3. Reino Unido: Sage Publications.

Fishman, Mark (1983) La fabricación de la noticia. Buenos Aires: Ediciones Tres Tiempos.

Gans, Herbert J. (1980) Deciding What's News. A study of CBS News, NBC Nightly News, Newsweek and Time. Nueva York: Vintage Books.

Gomis, Lorenzo (1991) Teoría del Periodismo. Cómo se forma el presente. Barcelona: Paidós Comunicación.

GonZÁLez Molina, Gabriel (1986) "Valores noticiosos: la distribución desigual del acceso periodístico", Avances de Investigación, núm. 3. Colima: Universidad de Colima.

- (1986a) "La cobertura del terremoto en México", Chasqui, núm. 20. Quito: CIESPAL, pp. 58-61.

_ (1987) "Noticieros televisivos de la TV comercial en México: los imperativos del raciocinio corporativo", Revista Cultura Contemporáneas, núm. 2, Programa Culturas Contemporáneas. Colima: Universidad de Colima.

—_ (1988) "Organización, burocracia y profesión: determinación institucional de las comunicaciones sociales", en Sánchez Ruiz (comp.), La investigación de la comunicación en México, logros, retos y perspectivas. Guadalajara: Edicom/Universidad de Guadalajara, pp. 217-230.

_ (1990) "Ser periodista en Televisa, una encrucijada de valores noticiosos", Umbral xxI, núm. 4. México: Universidad Iberoamericana, pp. 42-45. (1990a) The production of Mexican television news. The supremacy of Corporate Rationale, tesis doctoral. Gran Bretaña: Universidad de Leicester. 
GrossberG, Lawrence, Ellen Wartella, y Charles Whitney (1998) Media Making. Mass Communication in a Popular Culture. Nueva Delhi/Londres: Sage Publications.

HARRINGTON C., Lee (1998) "Is anyone else out there sick of the news?! 'TV viewers' responses to non-routine news coverage", Culture \& Society, vol. 20 núm. 3, Sage Publications.

Hernández Ramírez, María Elena (1991) "La producción de noticias en una organización radiofónica tapatía: Notisistema”, en Aceves, Arredondo y Luna (comps.), Radiodifusión regional en México. Guadalajara: Universidad de Guadalajara.

- (1992) “¿Qué son las noticias?”, Comunicación y Sociedad, núm. 14-15. Guadalajara: cerc-Universidad de Guadalajara.

—_ (1995) La producción noticiosa. Guadalajara: cucsh-Universidad de Guadalajara.

(1997) "La sociología de la producción de noticias. Hacia un nuevo campo de investigación en México", Comunicación y Sociedad, núm. 30. Guadalajara: DECS-Universidad de Guadalajara.

— (1997a) Sociología del periodismo. Antología. Guadalajara: cucsh-Universidad de Guadalajara.

— (2000) "La investigación sobre producción de noticias desde América Latina", en Orozco Gómez (coord.) Lo viejo y lo nuevo. Investigar la comunicación en el siglo XXI, Madrid.

HIRSCH, Paul (1980) "Occupational, organizational and institutional models in mass media research. Toward and Integrated Framework", Mass Communication Review Yearbook, vol. 1. Beverly Hills: Sage, pp. 265-294.

KanIss, Phyllis (1991) Making local news. Chicago y Londres: The University of Chicago Press.

LeÑero, Vicente, y Carlos Marín (1986) Manual de periodismo, Col. Tratados y manuales. México: Grijalbo.

Lozano Rendón, José Carlos (1995) Teoría e investigación de la comunicación de masas. México: Alhambra Mexicana.

MARTín Serrano, Manuel (1994) La producción social de comunicación, segunda edición revisada.

México: Alianza Universidad Textos.

McQuall, Denis (1994) Mass Communication Theory. Londres/Thousand Oaks/ Nueva Delhi: Sage Publications.

McNaIR, Brian (1998) Sociology of Journalism. Londres/Nueva York: Arnold Publishers/Oxford University Press.

Rотн, Andrew L. (1998) "Who makes the news? Descriptions of television news interviewees' public personae", Media Culture \& Society, vol. 20, núm. 1, Sage Publications.

SCHLESINGER, Phillip (1992) "Repensando la sociología del periodismo. Estrategias de las fuentes y límites del centralismo en los medios", Revista Culturas 
Contemporáneas, núm. 13-14, vol. 4, Programa de Culturas Contemporáneas. Colima: Universidad de Colima.

Sigal, Leon V. (1973) Reporteros y funcionarios. La organización y las normas de la elaboración de noticias, Col. Política y Comunicación, Ediciones Gernika.

Strentz, Herbert (1983) Periodistas y fuentes informativas, Col. Periodismo. Buenos Aires: Ediciones Marymar.

Thompson, John B. (1998) Ideología y cultura moderna. México: UAMXochimilco.

Tuchman, Gaye (1983) La producción de la noticia. México/Barcelona/Buenos Aires: Ediciones G. Gili.

- (1993) "Métodos cualitativos en el estudio de las noticias", en Jensen y Jankowski (eds.), Metodologías cualitativas de investigación en comunicación de masas. Barcelona: Bosch. Versión en inglés: (1991) "Qualitative methods in the study of news", en Jensen and Jankowski (eds.), A handbook of qualitative methodologies for mass communication research. Londres y Nueva York: Routledge.

Turow, Joseph (1983) "Local Television: Producing Soft News", Journal of Communication, vol. 33, núm. 2, EUA.

Villafañe, J., E. Bustamente, y E. Prado (1987) Fabricar noticias. Las rutinas productivas en radio y televisión. Barcelona: Editorial Mitre.

Wolf, Mauro (1987) La investigación de la comunicación de masas. Crítica y perspectivas. México: Instrumentos Paidós.

(1997) "Los emisores de noticias en la investigación sobre comunicación", Zer, Barcelona. 